\title{
Interviews
}

\section{Interview with Carl Hixson, Vice President of Digital Asset Management at McGraw-Hill Education}

\section{Carl Hixson}

has the overall responsibility for defining and directing technology systems, strategic planning and specific key implementations for all digital asset management (DAM) and digital publishing processes across the McGraw-Hill Education (MHE) segment as Vice President, Digital Asset Management. As leader of the GenX initiative, and Digital Publishing/Enterprise Content Management group, Carl is also responsible for the development of digital workflow processes and the integration of emerging digital technologies into the design of McGraw-Hill Education's enterprise content management systems. These digital systems will facilitate McGraw-Hill's digital transition, and ensure that the Company maintains its competitive lead in the global marketplace.

Keywords: digital publishing, $x \mathrm{ml}$, repository, content management, extensible schema, metadata

Abstract Recently, Michael Moon spent some time with Carl Hixson of McGraw-Hill Education, discussing the publishing technologies they employ and taking a look at the current state and new trends in DAM for the publishing industry.

Journal of Digital Asset Management (2008) 4, 5-12. doi:10.1057/dam.2008.1

MM: I'm here with Carl Hixson, VP Digital Asset Management at McGraw-Hill Education.

Carl, can you provide us with a summary of your background in terms of your particular background in DAM as starting point to this discussion?

CH: Sure, Michael.

I started out in the industry approximately 15-20 years ago, in the digital imaging space with Getty Images. Back when Getty was in the process of acquiring content and digitizing that content to evolve into what is now known as the Getty online environment. A wonderful opportunity to be really at the forefront of where I think digital technology, imaging and content converge.

I was with Getty Images for about five years. Following my time in Getty, I joined HBO (a Time Warner organization), and was there for close to seven years as their Executive Director of digital asset management. While at $\mathrm{HBO}$, my team successfully designed, implemented and ultimately supported what's known as their Digital Library. A wonderful experience, as well.

Both of these engagements enabled us to develop digital content management and ultimately enterprise content management systems for the media and entertainment space during the emergence of these technologies. My team at $\mathrm{HBO}$ developed a system that managed digital asset types that included rich media (photos/audio/video/animations), electronic documents, XML and web content.

We subsequently started to distribute content from those repositories to customer-facing environments like the HBO.com website and various other distribution channels.

A little over two years ago I joined the McGraw-Hill organization as Vice President, Digital Asset Management. My primary focus is to enable McGraw-Hill's digital transformation, and to develop systems that facilitate enterprise content management, custom publishing and an increased global presence.

McGraw-Hill has offices located in over 20 different countries. It's very much of a global operation. The transition from analog to digital content creation is something that McGraw-Hill has really embraced. My highly skilled team at MH is tasked with the assignment of developing the systems and distribution vehicles that will form the foundation of our digital platform.

In addition to that, we're also implementing a digital publishing toolset, which enables our 
content creators to start developing content in digital form. By tagging content during the development process we create digital masters of our products, as well as XML representations of that content.

The digital masters of both rich media and what we call "dynamic content" are subsequently fed into our asset-management repositories. Then we can do some very creative things - like develop custom publishing environments. The fulfillment of multi-channel distribution to various mediums is also attainable as a result of effectively creating dynamic content. Certainly content-repurposing comes to life, here. These achievements are possible at McGraw-Hill, even more so than my previous engagements, because of the sheer magnitude and richness of our content. The potential is unlimited.

So we are well along our developmental strategy and our implementation roadmap. Our digital asset library is in full production. Both the rich media and dynamic content repositories are both online and rapidly growing. We're just satisfying the Library's capacity for content by feeding to them both, as rapidly as we can.

This digital strategy is inline with McGrawHill's dedication to becoming more of a digital organization, and being able to leverage more of the global marketplace. Being intimately involved with the emergence and development of digital technology is both fascinating and rewarding.

MM: Would you spend a moment just describing some of the technology elements or piece parts of your content factory?

$\mathbf{C H}$ : We have what I like to call a best-of-breed architecture in place. It's very modular. We have partnered with several technology providers to develop our digital architecture. We have some compelling search technology in place to provide rapid retrieval of our digital content.

We obviously have very massive Oracle databases running on the back end, and we're using a lot of creative front-end elements, like Flex and Flash from Adobe and XQuery, to present an environment that provides a broad range of functionality, and remains seamless to the end user. MM: And publishing technologies or tools? $\mathbf{C H}$ : Basically, our publishing technology — I'll reference back to the digital publishing toolset - is largely focused around Adobe CS and K4. McGraw-Hill made the decision to migrate away from Quark QPS and standardize on the Adobe toolset several years ago.

MM: Do you have a specialized XML database?

CH: We have customized our Digital Asset Library instance to also function as our XML repository. As a result of strategic vendor partnerships, and internal application development, we try to tailor technology to provide us with optimal solutions (based on business requirements). Quite often we take a bit of technology and introduce our own layer of customizations, to bring us the rest of the way there. We take it as far as we can "out of the box." Then we introduce our development layer, in terms of customization, to really enable us to facilitate a solution based on what our particular business requirements dictate.

This is what I refer to as our "best of breed" approach.

MM: Do you work with a particular systems integration firm to do those customizations? Or do you do those internally?

CH: Fortunately, I have an internal team here of developers and DBAs and project managers and analysts that enable us to do most of our customizations. We develop most of our customizations in-house, and partner with systems integrators when necessary.

MM: Carl, if you would, can you put this into the larger context of a reprise or summarization of the state of publishing and media today? Specifically, the trend towards shifting to more of a digital business, and some of the implications of that - in terms of the care and feeding of the business.

$\mathbf{C H}$ : I think the publishing industry - more so than any that I've been involved with in my career so far - is now in the process of aggressively adopting this whole digital transition. I think the publishing industry stands to realize many benefits from the digital transformation, and McGraw-Hill is a premium example of an organization that will certainly benefit.

For 100 years, McGraw-Hill has been producing products (using traditional methods) very successfully, but has been very print-centric. Now with this whole paradigm shift embracing digital and becoming more of a digital organization, $\mathrm{MH}$ is realizing that digital is no longer a business luxury. It's a necessity. An endto-end digital transition is going to be required. 
It's going to be vital for McGraw-Hill and other publishers to continually develop a digital awareness, in order to maintain competitive in the social networking age. Additionally, I think McGraw-Hill will realize new potential revenue-generating opportunities, and ultimately more channels of which to deliver our vast resources of quality content.

The delivery format is not just print, any more. Print has now become one of several delivery options. A button that you push among other buttons out there that say, Okay, how would you like your content delivered? How would you like your content transformed? What shape, what size? What format would you like it in? The end users of today demand variety and dynamic choices with regard to the acquisition of content.

In the digital model, print is becoming one of many fulfillment options. When you're talking about digital distribution, the same content that produced the printed book should be able to be distributed out to the web, to a PDA device, to an e-book reader, et cetera - to a (future) device that hasn't even been developed yet.

By us positioning ourselves in the way that we are, and managing our content and creating content in the manner that we are (tagging the content and producing XML), it enables us to store that content in a neutral format that lends itself truly to multichannel distribution. I think that shift is being realized now, even more so in the publishing industry than media and entertainment.

When I was with $\mathrm{HBO}$, I always felt like we were the early adopters with regard to ECM technology. For a large part, the pioneers. That was exciting. It enabled us to do a lot of $R \& D$ and harnessing of emerging technologies. Now I'm seeing that the publishing industry is no longer laying back. With the emergence of Web 2.0 and user-generated content, publishers realize that they have to play in the digital space to remain competitive.

It's very interesting to see how the publishing industry truly stands to benefit from this digital evolution.

MM: One of the things we've seen in a number of organizations - even the scale of McGrawHill - has been what you referred to as a paradigm shift. I sometimes think of it as a mindset. In terms of how we create publications. Or how we create material.
As you alluded to in your previous remarks, print used to be the primary destination. Therefore, everything kind of got optimized. The workflow of production activities and so on. Management optimized to driving it to a print page.

Now it seems to me in the mindset, it's driving it to a database.

CH: I agree. The new digital workflow that is required as part of implementing digital publishing tools is largely focused on the generation of content in a neutral format that can be easily transformed. Database storage is quite often a central component of digital asset management systems. When content is effectively stored in a database it opens up potential for search, interoperability and custom publishing. The new mindset is perhaps driving towards "content versatility."

MM: Keeping it in a liquid moldable form — be it tagged XML content or reusable pieces of media. How has that changed the actual ideation and creation process for what ultimately gets published? Be it to a podcast or a book or a website or whatever?

CH: I think it's had a major impact, in terms of not only how content is being created but also the workflows that dictate the roles and responsibilities of the people that are creating the content.

I think, for example, authors have to now think, "digital." They have to become digital authors (in addition to maintaining their established expertise in print production).

MM: What does that mean?

CH: It means that authors now need to think about, "What are the benefits of XML? Why do I need to embrace XML? What additional skill set do I need to acquire to fully leverage XML? There's the traditional format of a book, but the same content now has to also publish out to the web. Or go to an e-book reader. What do I need to do and know as an author to be able to create content that lends itself to neutrality? As opposed to a specific (print) format..."

So now authors are not just developing a "book." They're authoring “content." That's really a mind shift, to your point. It's a process change. It is largely embracing a whole new content development process.

MM: How do you get an old dog to do a new trick? Or do you just find a bunch of new dogs that already know the new tricks? 
CH: Good question. Our approach has been a combination of education, evangelism, demonstration of benefits and knowledge transfer (user training).

MM: Ie... "As an author, I make more money?" $\mathbf{C H}$ :You certainly have the potential to generate additional revenue. You have an opportunity for the tail of the content to be much longer. I think you have the potential to even reach more users and readers than ever before. By leveraging the "long tail" we have the ability to reach a much larger audience.

My daughter's method of gathering content is a classic example. She now has several sources to refer to for research and access to information. She often turns to the web first, and then explores other options such as books and printed materials, television, etc. And the generation of today will often multi-task and consume multiple sources of content simultaneously. The demand for real-time information is apparent.

MM: Or a friend?

$\mathbf{C H}$ :Yes, her peers as well. The book has become one of many choices. The content creators (individuals that are creating the content) have to be aware of this fact. Once they are, it opens up new content development possibilities. Having an insight into the trends and demands of today and tomorrow will factor into the new process of how digital content needs to be developed.

It's not just the technology. Ensuring that the process change is associated with the development and implementation of technology is very important.

MM: It seems to me that as the web and the distribution channels and the business models continue to adapt to your daughter (and her generation) - the cognitive reality of your daughter and all her friends - it fundamentally begins to challenge or force a reassessment. Almost a reengineering of intellectual property. Of what an author creates.

CH: Absolutely.

MM: Can you speak to what some of the things are that you've learned at McGraw-Hill education? Primarily, the primary responsibility is creating textbooks and curricula. Is that correct? $\mathbf{C H}$ : That's correct. We're also developing online learning environments, homework-management systems, custom publishing tools and various other products from our many educational business units.

MM: So what are some of the "a-has" or insights that have bubbled up from that whole ideation and creation process, in terms of new forms of intellectual prop?

$\mathbf{C H}$ : Some of the more compelling concepts that have surfaced recently include content correlation systems, online learning environments, advanced search technology and the mapping of student profiles to dynamic assessment tools.

MM: Another way of saying that, Carl, is... "What can McGraw-Hill do to ingrain itself more deeply into the learning and cognitive process of students and teachers?"

CH: I think we have to start producing products that speak to who our new customers are, and position ourselves to establish education partnerships that last throughout their personal development lifecycle.

MM: Please elaborate...

$\mathbf{C H}$ : This concept would apply to my daughter and her friends. I think traditionally publishers like McGraw-Hill have targeted the school system, including the school superintendent, the administration, the principal and the various curriculum procurement departments.

Perhaps the FaceBooks and the MySpaces of the world have changed the landscape. Now, publishers like McGraw-Hill really need to become realigned with who the real customer is. And to produce products that address the needs of "new" customer. I think the new client is the child in the digital classroom. The student in the digital classroom requires more dynamic content. It's likely that they'll still have a need to purchase the book, but will also have a need for additional sources and formats of information...

The interactive research that a mediatechnology product provides. A CD or DVD that's included with the book. I think that's where - once again - content needs to be created to facilitate multi-media and multichannel distribution.

The students of today - even though they might not have the revenue, they have the influence. They influence the people that have the revenue that are ultimately going to be making the purchases.

We need to really understand what's going on in the classroom and understand what's 
going on in the mind of the student. This level of awareness of evolving market demands needs to correlate back to requirements gathering to ensure that innovation is a part of the system development process.

MM: So, Carl - another way of saying or reflecting back what you've just said.... The challenge for McGraw-Hill and other publishers of curriculum, books and learning objects and such... The real challenge before McGraw-Hill is really looking at the learning environment and emerging trends. What are all the dynamics and needs of the 2.0 learning environment? ... And identifying the product development strategy required to enhance your position as the premier provider of high-quality educational content.

CH: Unquestionably. And make sure that the demands for more interactive - more digital learning objects - are reflected in the developmental roadmap of our systems, our products and our services. Information gathering has to become more interactive. Just to reiterate, more inline with where the consumers of our content, our existing clients and new consumers are going to conduct their research and source their information.

MM: So in creating curriculum, I hear you making several key points. Firstly, we need to identify (tag) and itemize content into its structural components. For example, itemize curriculum into learning objects.

CH: Absolutely. The tagging of digital content into re-usable objects is a critical element. MM: Second, we need to do this in such a way that these learning objects can be correlated with content and presented as custom publishing frameworks. Learning frameworks. Some of these frameworks may be delivered online, as CD ROM products, or as a traditional textbook. The format of this content will lend itself to other distribution methods in the future.

$\mathbf{C H}$ : The above statement is completely inline with our digital strategy.

MM: Finally, the ability to look at the learning styles and profiles of individual consumers, and dynamically optimizing these objects and/or frameworks to particular learning styles.

$\mathbf{C H}$ : This is what our custom publishing and content correlation initiatives are designed to accomplish. Having the ability to map instructional content to assessment items will lead to learning analytics, and systems that will enhance the educational experience of students and teachers alike.

MM: Be they a reader-thinker or a talkerlistener type of individual, a visual versus an auditory thinker, or a visual thinker versus a watcher-doer type of person...

$\mathbf{C H}$ : Absolutely. And by creating and developing content to be truly dynamic, it lends itself to being able to facilitate all of the above.

MM: So that then comes back to the underlying metadata structure. How do you develop taxonomies and metadata schemas to reflect not just file properties and content, but things like learning objectives and cognitive learning styles? Additionally, ways of measuring the effectiveness and/or consumption of digital content by a particular learner in a particular learning environment?

$\mathbf{C H}$ : That's compelling. That's a very important point. In our approach, we've developed a very dynamic and extensible schema and metadata model at MHE. It's become our (McGraw-Hill) standard meta-model, and is utilized to tag and index our dynamic content. The attributes are all very much in line with our industry and business specific requirements. By design, the schema is very extensible. The same schema is also reflected in our digital asset management systems.

So when new opportunities present themselves, guess what? Our schema reflects that.

Our enterprise content management system is made up of multiple (best of breed) modules. However, we have one common schema (framework) that's implemented across all of the repositories. So that one standard is very absolute. As dynamic as it is, it's absolutely reflected (down to the attribute) in all of our enterprise content-management systems.

So that's the way that we can maintain consistency and make sure that we stay true to our standard. This model also facilitates federated search across various environments. This method allows us to keep ourselves open and flexible enough to address new content development and distribution opportunities when they present themselves.

MM: One of the things that we've seen, Carl, has been the notion of the open or networked publication. Specifically, the potential for opensource user-generated content or user-generated 
feedback interacting with professionally generated content.

$\mathbf{C H}$ : Yes. We have to be very conscience of user-generated content and the emergence of social networking and Web 2.0. There are many opportunities as well as concerns for content providers that enter this arena. For example, copyright protection for professionally generated content is something that must be addressed when these assets co-exist with user-generated information.

MM: In particular, one of the things we're seeing is something we see a lot of in the academic journal space. Content that is more specific to a very targeted or narrowly defined community of subject matter experts or practitioners.

CH: Definitely... User-generated content environments offer the ability to publish customized information that's tailored to a specific audience or topic. That offers a great opportunity for McGraw-Hill to leverage its rich volume of content and establish online custom publishing systems. These systems (driven by XML) would have the ability to generate niche content to a vast user base, resulting from very specific queries.

MM: But specifically, where an author begins to create a book (a curriculum or some sort of a work) and then opens it up to comment.

Perhaps using a Wiki or other sorts of collaboration tools. Inviting dozens, hundreds, maybe even thousands of people to comment if not outright edit, change, augment, annotate specific passages of a work. This would necessitate the editor to sift through, edit, incorporate and ultimately to refine and optimize an authored passage to reflect an ad hoc peer review.

CH: My immediate response is... How does McGraw-Hill embrace that? Should we embrace it? How do we incorporate that? How do we play in that space without de-valuing our content and/or our creditability?

MM: How do you avoid being run over by that runaway bus?

CH: Exactly. Does it add value? How can it add value to the very high quality content that McGraw-Hill has been producing traditionally for a considerable amount of time?

MM: What have been some of the early conclusions from that?
$\mathbf{C H}$ : We realize that we have to have a presence in that arena. The concern is how do we maintain integrity? How do we maintain certain levels of quality? How do we maintain our responsibilities with regard to copyrights? Security and rights management is a major concern.

If authors are being paid to generate content for McGraw-Hill, and there's a certain amount of integrity and quality that comes with that content - how does that content intermingle with user-generated content? Or should it intermingle? How do we enable a seamless integration or collaboration with the online community concept, where basically it's free reign. Everyone has the ability to publish and edit.

If you're savvy enough or if you have an interest, you go ahead and submit content. How do we ensure a certain level of quality? How do we ensure that the quality of our professionally created content is maintained? That's not saying that user-generated content cannot also be high quality.

These are some of the questions that we're asking ourselves. But we do realize that this space is here. It's here to stay. And I think we see more and more environments coming online. New wikis and blogs are coming online at an increasing rate. It's clear that we're going to have to continue to include this medium in our overall strategy.

MM: Any early indications of how?

$\mathbf{C H}$ : Although we're taking a close look at this space, the strategy is evolving, and it may be too early to tell.

MM: Fair enough.

The most interesting question for me in this conversation and other related conversations really gets to, "What is value?" In terms of editorial product, copy, learning objects. What really constitutes or comprises a valuable piece of content?

CH: I think two important factors that determine the value of content is its revenue generating potential, and re-usability.

MM: That's your business model speaking.

$\mathbf{C H}$ : Those elements are certainly part of our core digital strategy.

MM: That's not your daughter's talk.

CH: No. And I would also add reliability. Does the information that I gathered adequately 
answer a question? Does it solve or satisfy my research? Does it fulfill my query? Those are all important measurement criteria.

MM: Has McGraw-Hill or have you seen any kind of development or emergence of a general theory of information objects? Or a general theory of information consumption? In terms of categories of content?

$\mathbf{C H}$ :Yes I do. An example if this is the ability to correlate instructional content to State standards and learning objectives. Content consumers will require content categorization and management systems that will enable searching by learning objectives. Additionally, with other methods of categorization, consumers will be able to submit a query for educational content based on a specific State standard.

One of the challenging things that educational publishers face is that every State has a different standard. A book that was developed for the State of California would not be acceptable to the State of Florida - for many reasons. But there are different standards involved. We have to be very cognizant of that when content is being developed.

The short answer to your question is yes. Having the ability to categorize content, to have content become dynamic, mapping content to state standards and assessment items are all critical functions that will enable McGraw-Hill offer new tools and services.

Having the ability to assess the learning abilities of students, as well as the effectiveness of teaching methods is critical to the progression of the educational process. We must have a form of measurement and corrective processes in place to establish a standard for achievement, and continually strive for educational excellence. Categorization and distribution of "smart content" will help both students and teachers accomplish their learning objectives.

MM: How do you manage that complex correlation?

$\mathbf{C H}$ : There's a framework involved that we're in the process of developing. Once we know what the State standards are, then we can go about the business of mapping our content to those State standards.

MM: Are you going to be using a policy server or a business rules engine?

$\mathbf{C H}$ : Rules engines, policy servers and right management are all components of our enterprise content management development strategy. The framework essentially becomes part of our asset library. The business logic is an architectural layer that interoperates with the core system. You can see where we're going.

So to your original question of, "How do we see categorizing content, learning objectives, et cetera..." This is compelling for us, because we truly believe that this opens up a whole new realm of content development and product development possibilities.

MM: This is a great place to close on a remark I heard attributed to ERP. ERP being Enterprise Resource Planning.

$\mathbf{C H}:$ Yes... Please continue...

MM: One definition of ERP is a salesman in a customer's office can make a promise that the factory can keep.

$\mathbf{C H}$ : I understand the analogy, and can see how it applies to the media \& information industry. MM: When you think about a textbook salesman out there repping your textbooks, they can make a promise to a particular school system and know - with confidence - that your content factory can fulfill a promise that your salesman is making. Using the content factory and all the rules and correlations by which you characterize content down to its atomic level.

$\mathbf{C H}$ : That's exactly within the view of our strategic vision. That's where we're headed.

When we say, "dynamic content," it has a far-reaching definition. But you've just basically summarized what we're really going after, here. I think McGraw-Hill and other publishers like McGraw-Hill really stem to benefit from a meaningful adoption of this digital technology, and the transition that's happening as a result.

MM: As the ideation and creation process produces more brightly lit, fully profiled, independent learning objects, perhaps we should think about retiring the term, "content," and more specifically — as you refer to your forward-looking focus as "dynamic content..." Not that I have a big say in it, but I perhaps you speak in terms of "dynamic learning objects," or, "dynamic learning environments." CH: I think that all of the above terms are relevant. Content is still content... However the potential that's unleashed once the content is created in a format that enables re-purposing and correlation, it creates the dynamic aspects. 
Once content is dynamic, those qualities can be applied to learning objects, environments and interactive user experiences.

MM: Then you're no longer in the content business, but you're in the business of structuring and provisioning learning environments with resources and fixtures in the specific requirements and needs of an individual learner or user.

$\mathbf{C H}$ : Sure. In addition to being in the business of creating high quality educational content, McGraw-Hill is also developing new and innovative learning solutions based on emerging digital technology. As we become more and more in tune with the mindset of our clients and demands of the global marketplace, we reflect that awareness in our developmental strategies.

I think you're going to see more and more of those "dynamic environments" becoming a part of our digital offerings.

MM: On that note, I think we'll call it a day, here.

CH: All right, my friend. Thank you for the opportunity to explore the possibilities and engage in the dialog. 